\title{
Pathogenicity of Aster Yellows Phytoplasma and Spiroplasma citri on Periwinkle
}

\author{
Chung-Jan Chang
}

Department of Plant Pathology, College of Agricultural and Environmental Sciences, University of Georgia, Griffin Campus, Griffin 30223. Accepted for publication 11 September 1998.

\begin{abstract}
Chang, C.-J. 1998. Pathogenicity of aster yellows phytoplasma and Spiroplasma citri on periwinkle. Phytopathology 88:1347-1350.

Using Murashige and Skoog (MS) as a basal medium, the effects of varying levels and combinations of plant growth regulators required for shoot tip and root proliferation in healthy and aster yellows phytoplasma (AYP)- and Spiroplasma citri-infected periwinkle (Catharanthus roseus) shoots were studied. Number of shoots and fresh and dry mass of healthy and AYP-infected shoots increased when benzyladenine (BA) concentrations were increased from 0.5 to $4 \mathrm{mg} /$ liter. The maximum number of shoots for both healthy and AYP-infected plants was obtained when grown in MS medium supplemented with BA at $4 \mathrm{mg} / \mathrm{liter}$ and indole-3acetic acid (IAA) at $0.5 \mathrm{mg} /$ liter. $S$. citri-infected shoots proliferated the most when grown in MS medium containing BA at $2 \mathrm{mg} /$ liter and IAA at $0.5 \mathrm{mg} / \mathrm{liter}$. The best medium for root production in healthy periwinkle shoots contained $\alpha$-naphthaleneacetic acid (NAA) at $0.5 \mathrm{mg} / \mathrm{liter}$, whereas the best medium for AYP-infected shoots contained indole-3-butyric acid (IBA) at $2.5 \mathrm{mg} / \mathrm{liter}$, both in combination with kinetin at $0.1 \mathrm{mg} / \mathrm{liter} . S$. citri-infected shoots had the best root growth when grown in medium

concentration of cytokinin and auxin needed for maximum shoot proliferation differed between AYP- and S. citri-infected shoot tips, strongly indicating that the two mollicutes may cause different changes in endogenous cytokinin and auxin levels. The concentrations of NAA and IBA needed for root growth of S. citri-infected shoots were two- to fivefold higher than the concentrations needed for healthy and AYP-infected shoots, clearly demonstrating that $S$. citri infection caused a shortage of auxins that resulted in retardation of secondary root growth. Chlorophyll content was markedly reduced in periwinkles infected with AYP or S. citri compared with chlorophyll in healthy periwinkles. AYP caused a decrease in carotenoid in leaves 6 weeks after graft-inoculation, but carotenoid content was unchanged in $S$. citri-infected leaves throughout the test period. Anthocyanin content in periwinkles infected with AYP decreased significantly by 4 weeks postinoculation, whereas anthocyanin content in periwinkles infected with $S$. citri increased. Anthocyanin content in leaf tissues, however, was reduced as a result of AYP and $S$. citri infection. Pigment changes induced by AYP and S. citri, whether similar or different compared with those of healthy periwinkle shoots, provide important information for interpreting pathogenesis when linked with plant growth regulators.
\end{abstract} supplemented with IBA at $5.0 \mathrm{mg} / \mathrm{liter}$ and kinetin at $0.1 \mathrm{mg} / \mathrm{liter}$. The
This review summarizes recent developments in the study of the pathogenicity of aster yellows phytoplasma (AYP) and Spiroplasma citri on periwinkle (Catharanthus roseus). Different theories have been reported in previous reviews $(8,9,13)$. The effects of phytoplasma infection-impairment of phloem function, alteration of turnover rate of hormones, low level of indole-3-acetic acid (IAA) oxidase activity, increase or depletion of hormone precursors, presence of inhibitors of hormone synthesis, hormone transport or translocation, and selective uptake and transport of hormones - are associated with disease development. In S. citri infection, several components play a role in disease development: toxins with molecular weights $<300$ to $400(7,11)$, accumulation of lactic acid (19), and proteolysis and arginine aminopeptidase enzymatic activity. Daniels and Meddins (11) used an algal assay to monitor purification of a toxic substance in S. citri cultures. The toxin was found in the soluble fraction of disrupted cells with molecular weights $\leq 300$. Further chemical characterization of the toxin has

Corresponding author: C.-J. Chang

E-mail address: cchang@gaes.griffin.peachnet.edu

Publication no. P-1998-1023-010

(C) 1998 The American Phytopathological Society been frustrated by its instability and the difficulty of separating it from contaminating substances carried over from the growth medium. A parallel series of experiments was designed using a broad bean leaf bioassay (7). The active component defined by the broad bean leaf bioassay is acidic in character, with a molecular weight $<400$. Little definitive information on the active component is available, in part because of the apparent instability of the material in semipurified preparations.

To date, there have been no conclusively demonstrated mechanisms that explain the pathogenicity of AYP and S. citri, and some researchers have questioned the theories mentioned. For instance, the toxin found in $S$. citri culture extract was found in fresh spiroplasma growth medium used in the algal bioassay $(8,11)$. The broad bean leaf assay seemed to provide evidence of the toxic substance extracted from $S$. citri culture, but alternate host tissue was tested, not host citrus tissue. In the growth medium of Saglio et al. (19), the lactate concentration reached 5 to $10 \mathrm{mM}$ after cell density reached $\approx 2 \times 10^{9} \mathrm{CFU} / \mathrm{ml}$. If metabolites diffuse freely throughout the plant, the average lactate concentration could reach 20 to $50 \mathrm{mM}$, assuming the metabolism of spiroplasmas in the plant is similar to that in culture. It is possible, therefore, that lactate production by spiroplasmas in heavily infected plants may contribute to disease symptoms (8). However, no report is available to 
sustain the theory that high lactate concentration produced by $S$. citri actually induces disease symptoms.

Imbalances in plant growth regulator levels have been theorized as playing a role in various symptoms, including dwarfing and stunting, chlorosis, virescence, and phyllody, that develop in diseased plants (6). However, only a few reports have described the interaction between growth regulators and symptom development (4-6,10,13,22-24). My review focuses on recent efforts to understand the effect of plant growth regulators on symptom development induced by AYP and $S$. citri, including a comparison of pigment changes in periwinkle plants during the course of symptom development. For the first time, symptom development caused by AYP and $S$. citri is compared under the same conditions. The use of shoot-tip tissue cultures in studying the pathogenicity of AYP and S. citri is unprecedented.

\section{AYP AND S. CITRI}

Mollicute is the common name for wall-free, prokaryotic microorganisms of the class Mollicutes (20). Mollicutes range in size from 175 to $250 \mathrm{~nm}$ in diameter during reproduction but grow to various sizes and shapes later. Mollicutes lack a true cell wall and are bounded by a single triple-layered "unit" membrane. Their small or ultramicroscopic cells contain cytoplasm, randomly distributed ribosomes, and strands of nuclear material. Mollicutes are described as pleomorphic prokaryotes, which means that during their life, their shapes range from coccoid or slightly ovoid to filamentous or helical. They reproduce by budding and binary fission.

Two types of wall-less prokaryotes infect plants: spiroplasmas are characteristically helical and cultivable, and phytoplasmas (formerly mycoplasmalike organisms) are noncultivable and probably nonhelical. Spiroplasmas were recognized as a new microbial entity during the 1970s, when they were found to be associated with two plant diseases: corn stunt and citrus stubborn. A spiroplasma was later reported to be a causal agent of brittle root of horseradish and a periwinkle disease (21). In contrast, phytoplasmas have been cited as the causal agents of more than 300 diseases in several hundred plant species (16).

S. citri causes stunting, chlorosis of foliage, loss of apical dominance, and poor yield on citrus. Poor yield is a consequence of small, misshapen fruits with poor taste that carry aborted seeds. $S$. citri, however, does not cause virescence and phyllody, wilting, or death of citrus (2), primarily because few $S$. citri cells are found in the phloem of infected citrus (8).

Symptoms on periwinkle infected by $S$. citri include remarkably reduced leaf and flower size, wilting, and eventual death of infected plants. It has been suggested that high titers of spiroplasma cells in the phloem of infected periwinkle cause wilting and death $(8,10,15)$. As with citrus infection, $S$. citri does not cause virescence and phyllody symptoms on periwinkle.

Plants infected by phytoplasmas show general symptoms of stunting due to decreased internode growth, reduced foliar size, and decreased growth rate and additional characteristic phytoplasma interaction symptoms. Symptoms that develop on AYP-infected periwinkle can be used as an example. Floral symptoms often consist of virescence or petal greening; phyllody, in which petals and sepals become leaflike; and eventual cessation of flower production. Witches'-broom often develops, either through production of vegetative shoots from AYP-infected floral organs or proliferation of lateral branches. Other symptoms include leaf deformation and discoloration, root and leaf necrosis, proliferation of adventitious buds, changes in internode length, and abnormal flower induction (6).

When symptoms induced by $S$. citri and AYP on periwinkle are compared, one wonders (i) why $S$. citri causes wilting and death of infected plants, and AYP does not; and (ii) why S. citri does not cause virescence and phyllody on infected flowers, and AYP does. In 1994, a study was performed to compare the growth of healthy and S. citri- and AYP-infected periwinkle plants (5). Periwinkle plants were graft-inoculated with scions infected with either $S$. citri or AYP. Three plants each of healthy and S. citri- and AYPinfected periwinkle were sampled for fresh and dry weight of leaves, stems, and roots. The length of stems and roots also was measured. Samples were taken $0,4,6,8,10,12$, and 14 weeks after graft-inoculation. Plants were removed from pots and washed carefully with running water to remove soil. Damage to roots during washing was minimized.

Based on the dry weight/fresh weight ratios of combined stems and leaves, there was no significant difference among healthy and $S$. citri- and AYP-infected periwinkle plants for up to 14 weeks, indicating distorted tissues weighed as much as unaffected tissues, even after typical symptoms had developed fully (6 to 8 weeks after inoculation). In root growth, no difference was observed between healthy and AYP-infected plants through 14 weeks after inoculation. Significant increases (20 to $35 \%$ ) in the dry weight/fresh weight ratio of roots in $S$. citri-infected plants occurred by week 12 compared with ratio for healthy and AYP-infected plants, indicating a significant decrease in the water content of the root system of $S$. citri-infected plants. Significantly shorter stems began to appear in S. citri-infected plants by week 10 after inoculation, even though no difference was observed in stem length up to week 8 . At week 14, the stem length of healthy and AYP- and S. citri-infected periwinkles was 60,57 , and $48 \mathrm{~cm}$, respectively. However, significantly longer roots began to develop in $S$. citri-infected plants by week 12 . By week 14 after inoculation, the root length of healthy and AYP- and $S$. citri-infected periwinkles was 41,40 , and $49 \mathrm{~cm}$, respectively. Even though the primary roots of $S$. citri-infected plants were longer than those of healthy and AYP-infected plants, growth of secondary roots was poor. Results seemed to indicate that wilting of $S$. citri-infected plants was the result of retarded secondary root growth (5).

In 1995 a study was conducted to investigate shoot-tip cultures of periwinkles infected by AYP- and $S$. citri (4). Shoot tips $(1 \mathrm{~cm})$ of infected as well as healthy periwinkle plants were grown in Murashige and Skoog medium (18) containing $\alpha$-naphthaleneacetic acid (MS1N) at $1 \mathrm{mg} /$ liter. Shoot tips of AYP-infected as well as healthy plants had normal shoot and root growth, whereas those of $S$. citri-infected plants had callus growth and shoot proliferation with limited growth of root primordia after 11 weeks in MS1N medium. The dry weight/fresh weight ratios of stems and leaves were $0.12,0.15$, and 0.24 for healthy and AYP- and S. citri-infected plants, respectively. The dry weight/fresh weight ratios of roots were 0.06 , 0.11 , and 0.18 for healthy and AYP- and S. citri-infected plants, respectively; however, the latter ratio represented more root primordia and callus than actual root. S. citri infection caused retardation of root growth in MS1N medium compared with either healthy or AYP-infected plants (4).

Retardation of root growth by $S$. citri infection was obvious in both greenhouse-grown and shoot-tip cultures of periwinkles. Growth and development in plants is controlled by biologically active endogenous compounds, such as IAA (auxin), indolic-related compounds, gibberellins (GA), cytokinins, ethylene, abscisic acid, and others. A study was designed to test the effects of various combinations of auxins and cytokinins on shoot and root proliferation of shoot tips from healthy and AYP- and S. citri-infected plants. For shoot proliferation, various concentrations of benzyladenine (BA) were combined with IAA in Murashige and Skoog (MS) basal medium (22). For root proliferation, MS basal media containing $\alpha$ naphthaleneacetic acid (NAA) or indole-3-butyric acid (IBA) at various concentrations in combination with various concentrations of kinetin were tested. The number of roots and length of roots and shoots were measured 8 weeks after microshoots were transferred to rooting media $(23,24)$.

The number of shoots and fresh and dry mass of healthy and AYP-infected periwinkle shoots increased when BA was increased from 0.5 to $4.0 \mathrm{mg} / \mathrm{liter}$. When BA was supplemented at $8 \mathrm{mg} / \mathrm{liter}$, it became inhibitory to growth of healthy and AYP-infected shoots. 
The number of shoots and fresh and dry mass of $S$. citri-infected shoots increased when BA was increased from 0.5 to $2.0 \mathrm{mg} / \mathrm{liter}$. When BA was supplemented at 4 or $8 \mathrm{mg} / \mathrm{liter}$, it became inhibitory to growth of $S$. citri-infected shoots. The maximum number of shoots for both healthy and AYP-infected plants was obtained when grown in MS basal medium supplemented with BA at $4 \mathrm{mg} / \mathrm{liter}$ and IAA at $0.5 \mathrm{mg} / \mathrm{liter}$. $S$. citri-infected shoots proliferated the most when grown in a medium with BA at $2 \mathrm{mg} /$ liter and IAA at $0.5 \mathrm{mg} / \mathrm{liter}(23,24)$.

NAA alone or in combination with kinetin promoted rooting in healthy and AYP-infected shoots. The best medium for root production in healthy shoots contained NAA at $0.5 \mathrm{mg} / \mathrm{liter}$, whereas the best medium for AYP-infected shoots contained IBA at $2.5 \mathrm{mg} / \mathrm{liter}$, both in combination with kinetin at $0.1 \mathrm{mg} / \mathrm{liter}$. When NAA was used as the sole auxin source, $S$. citri-infected shoots grew roots only a medium containing NAA at $2.5 \mathrm{mg} /$ liter. IBA seemed to initiate better root growth for $S$. citri-infected shoots than NAA. $S$. citri-infected shoots had the best root growth when grown in a medium with IBA at $5 \mathrm{mg} /$ liter and kinetin at $0.1 \mathrm{mg} / \mathrm{liter}$ $(23,24)$.

The cytokinin and auxin requirements of AYP-infected shoots were similar to those of healthy shoots but different from those of $S$. citri-infected shoots. For example, to induce shoot proliferation, the best BA/IAA ratio was $4: 1$ for $S$. citri-infected shoots and 8:1 for healthy and AYP-infected shoots. Compared to healthy and AYPinfected periwinkle shoots, $S$. citri-infected shoots were less affected by different combinations of auxin and cytokinin and could tolerate a high concentration of BA, up to $8 \mathrm{mg} / \mathrm{liter}$. When grown in medium containing BA at $8 \mathrm{mg} /$ liter, the mean number of shoots for $S$. citri-infected shoot tips reached $50.3 \%$ of the maximum number obtained when BA was added at $2 \mathrm{mg} / \mathrm{liter}$; healthy and AYP-infected shoot tips only reached 10.6 and $26.2 \%$, respectively, of the maximum number obtained when BA was added at $4 \mathrm{mg} / \mathrm{liter}$. Davey et al. (12) reported that phytoplasma infection caused a reduction in cytokinin in mature leaves and roots and an increase in flowers. In rooting media, higher concentrations of auxins were needed for $S$. citri-infected shoots to grow roots compared with healthy and AYP-infected shoots. Because S. citri infection induced bud differentiation in BA medium and suppressed root initiation at lower concentrations of auxins, $S$. citri infection may increase endogenous cytokinins or reduce endogenous auxins (23).

AYP-infected shoots were responsive to various NAA and IBA concentrations, whereas $S$. citri-infected shoots were responsive to higher auxin concentrations. Results suggest that AYP infection may alter the content of endogenous auxin. The highest rooting levels were found in AYP-infected shoots, not in S. citri-infected or healthy shoots. Also, the strong response of AYP-infected shoots to exogenous auxin shows that AYP-infected shoots were significantly longer than both healthy and S. citri-infected shoots. In shooting media, although AYP-infected and healthy shoots required the same ratio of cytkinin to auxin, the number of shoots and dry mass of AYP-infected shoots were significantly less than for healthy shoots. Reduced growth of AYP-infected shoots in media also suggests that AYP infection is associated with alteration of endogenous auxin levels. Biosynthesis of auxin is centered in young leaves and shoot tips and is basipetally transported in the phloem, where the AYP pathogen is located. AYP infection may block the transport of auxin and reduce endogenous auxin levels in periwinkle, which would cause infected periwinkle to display a relatively greater response to exogenous IAA (23).

Foliar chlorosis is a common symptom caused by AYP and $S$. citri. Pigment alterations may be involved in pathogenesis. A study was conducted to analyze pigment content, including chlorophyll, carotenoid, and anthocyanin. Grafting-inoculation was used to prepare AYP- and S. citri-infected periwinkles. Five plants each from healthy and AYP- and S. citri-infected periwinkles were sampled biweekly, beginning at 2 weeks after infection for up to 20 weeks, for pigment analysis (23). Chlorophyll a, chlorophyll b, and total chlorophyll contents were markedly reduced in both AYP- and $S$. citri-infected periwinkles. In AYP-infected periwinkles, yellowing of leaves seemed to begin with older leaves, suggesting the reduction in chlorophyll is predominantly due to the destruction of these pigments in mature chloroplasts. The reduction of chlorophyll occurred before yellowing symptoms became visible in $S$. citri-infected periwinkle leaves, indicating $S$. citri may interfere in biosynthesis (23).

Compared with healthy leaves, the carotenoid content in AYPinfected leaves began to diminish 6 weeks after infection, whereas carotenoid content in $S$. citri-infected leaves remained unchanged for up to 20 weeks after infection. The anthocyanin content in flowers infected with AYP significantly decreased as virescence symptoms developed, whereas anthocyanin content in flowers infected with $S$. citri increased significantly. Anthocyanin content in leaf tissues decreased significantly in both AYP- and S. citri-infected tissues compared with anthocyanin content in healthy leaf tissues. The significant reduction in anthocyanin content in leaves and flowers occurred as early as 4 weeks after infection (23).

Mevalonic acid (MVA), isopentenyl pyrophosphate (IPP), geranyl pyrophosphate, and farnesyl pyrophosphate are key intermediates in biosynthesis of sterols,. Spiroplasmas depend on plant sterols for growth (3). Therefore, the constant demand for sterols should make spiroplasma-infected plants consume more IPP than healthy plants. IPP is also a precursor for biosynthesis of cytokinin (17); as a result, there could be competition for IPP that would upset the balance of cytokinin in infected plants. Because MVA is a precursor for both IAA and IPP, the constant demand for IPP for sterols also would upset the balance of IAA.

MVA, IPP, and geranyl geranyl pyrophosphate (GGPP) are intermediates in biosynthesis of carotenoids (1), GA, and chlorophyll. Therefore, as long as PP is used to make sterols to satisfy the needs of the plant and growth of AYP or S. citri, there will be a shortage of IPP for cytokinin, GA, chlorophyll, and carotenoids in AYPand $S$. citri-infected plants. The reduction in chlorophyll in AYPand $S$. citri-infected periwinkles and in carotenoid in AYP-infected plants supports this assumption. The successful remission of dwarf symptoms by applying GA to China asters infected with aster yellows and hybrid sweet corn infected with corn stunt demonstrates the shortage of GA in infected plants $(6,14)$. Why the content of carotenoid in $S$. citri-infected plants remained unchanged is unknown. Further investigation to devise methods to exploit the mechanism of carotenoid reduction by AYP and development of virescence and phyllody in periwinkle flowers by AYP is warranted.

\section{CONCLUSIONS}

For the first time, the pathogenicity of AYP and S. citri was investigated by looking at the effects of plant growth regulators on growth of healthy and AYP- and S. citri-infected periwinkles, using a shoot-tip tissue culture system. Shoot-tip tissue cultures proved to be useful, because both the concentration and combination of various plant growth regulators could be monitored precisely. The concentrations of cytokinin and auxin needed for best shoot proliferation differed between AYP- and $S$. citri-infected shoot tips, strongly indicating that these mollicutes may cause different changes in endogenous cytokinin and auxin levels. The concentrations of NAA and IBA needed for root growth of $S$. citri-infected shoots were two- to fivefold higher than the concentrations needed for healthy and AYP-infected shoots, which clearly demonstrated that $S$. citri infection caused the shortage of auxins that resulted in retardation of secondary root growth. Retardation of secondary roots may explain why $S$. citri-infected periwinkles grown in a greenhouse take longer time to develop wilt (6 to 12 months) and eventual death (1 to 2 years or longer) (C. J. Chang, unpublished data). Because $S$. citri essentially requires the supplementation of plant sterols for growth, the constant demands for sterols by $S$. citri would create a sink that causes greater use of common inter- 
mediate components that both plant sterols and plant growth regulators need. In contrast, AYP, which is presumably plant sterol-dependent similar to $S$. citri, does not cause wilting and death on periwinkles. AYP infection did not cause retardation of secondary root growth in greenhouse-grown periwinkles $(4,5)$, and AYP-infected shoot tip cultures behaved more like healthy cultures in response to plant growth regulators, which explains why no wilting or death occurred.

In addition to other approaches, such as searching for genes for pathogenicity or for genes encoding plant growth regulators or hormone-like molecules, that are currently being pursued in the study of the pathogenicity of AYP and S. citri, the shoot-tip tissue culture system is an ideal tool for further study of the interactions of plant growth regulators and disease symptom development. For the first time, the pigment alterations of periwinkles induced by AYP and $S$. citri infection were compared with healthy plant pigments during the course of symptom development under the same environmental conditions and time frames. Pigment changes induced by AYP and $S$. citri, whether similar or different to those of healthy periwinkles, provide important information for interpreting pathogenesis when linked with plant growth regulators.

\section{LITERATURE CITED}

1. Bramley, P. M. 1993. Carotenoid biosynthesis. Pages 281-297 in: Methods in Plant Biochemistry. Vol. 9. Academic Press, New York.

2. Calavan, E. C., and Oldfield, G. N. 1979. Symptomatology of spiroplasmal plant diseases. Pages 37-65 in: The Mycoplasmas. Vol. 3. R. F. Whitcomb and J. G. Tully, eds. Academic Press, New York.

3. Chang, C. J. 1989. Nutrition and cultivation of spiroplasmas. Pages 201241 in: The Mycoplasmas. Vol. 5. R. F. Whitcomb and J. G. Tully, eds. Academic Press, New York.

4. Chang, C. J., and Chen, M. 1995. Shoot tip cultures of periwinkles infected by Spiroplasma citri or aster yellows phytoplasma. (Abstr.) Phytopathology 85:1156.

5. Chang, C. J., Donaldson, R., and Wilkinson, R. E. 1994. Growth comparison between Spiroplasma citri-infected and aster yellows mycoplasmalike organism-infected periwinkles. IOM Lett. 3:276-277.

6. Chang, C.-J., and Lee, I.-M. 1995. Pathogenesis of diseases associated with mycoplasma-like organisms. Pages 237-246 in: Pathogenesis and Host Specificity in Plant Diseases. Vol. 1. U. S. Singh, R. P. Singh, and K. Kohmoto, eds. Elsevier Science Publishing Co., New York.

7. Daniels, M. J. 1979. A simple technique for assaying certain microbial phytotoxins and its application to the study of toxins by Spiroplasma citri. J. Gen. Microbiol. 114:323-328.

8. Daniels, M. J. 1979. Mechanisms of spiroplasma pathogenicity. Pages
209-227 in: The Mycoplasmas. Vol. 3. R. F. Whitcomb and J. G. Tully, eds. Academic Press, New York.

9. Daniels, M. J. 1983. Mechanisms of spiroplasma pathogenicity. Annu. Rev. Phytopathol. 21:29-43.

10. Daniels, M. J., Markham, P. G., Meddins, B. M., Plaskitt, A. K., Townsend, R., and Bar-Joseph, M. 1973. Axenic culture of a plant pathogenic spiroplasma. Nature (Lond.) 244:523-524.

11. Daniels, M. J., and Meddins, B. M. 1974. The pathogenicity of Spiroplasma citri. Colloq. INSERM 33:195-200.

12. Davey, J. E., Van Staden, J., and DeLeeuw, G. T. N. 1981. Endogenous cytokinin levels and development of flower virescence in Catharanthus roseus infected with mycoplasmas. Plant Pathol. 19:193-199.

13. Gabridge, M. G., Chandler, K. F., and Daniels, M. J. 1985. Pathogenicity factors in mycoplasmas and spiroplasmas. Pages 313-351 in: The Mycoplasmas. Vol. 4. S. Razin and M. F. Barile, eds. Academic Press, New York.

14. Maramorosch, K. 1957. Reversal of virus-caused stunting in plants by gibberellic acid. Science 126:651-652.

15. Markham, P. G., and Townsend, R. 1974. Transmission of Spiroplasma citri to plants. Colloq. INSERM 33:201-206.

16. McCoy, R. E., Caudwell, A., Chang, C. J., Chen, T. A., Chiykowski, L. N., Cousin, M. T., Dale, J. L., de Leeuw, G. T. N., Golino, D. A., Hackett, K. J., Kirkpatrick, B. C., Marwitz, R., Petzold, H., Sinha, R. C., Sugiura, M., Whitcomb, R. F., Yang, I. L., Zhu, B. M., and Seemuller, E. 1989. Plant diseases associated with mycoplasma-like organisms. Pages 546-640 in: The Mycoplasmas. Vol. 5. R. F. Whitcomb and J. G. Tully, eds. Academic Press, New York.

17. Moore, T. C. 1979. Biochemistry and Physiology of Plant Hormones. Springer-Verlag, New York.

18. Murashige, T., and Skoog, F. 1962. A revised medium for rapid growth and bioassay with tobacco tissue cultures. Physiol. Plant 15:473-497.

19. Saglio, P., L'Hospital, M., Lafleche, D., Dupont, G., Bove, J. M., Tully, J. G., and Freundt, E. A. 1973. Spiroplasma citri gen. and sp. n.: A mycoplasma-like organism associated with stubborn disease of citrus. Int. J. Syst. Bacteriol. 23:191-204.

20. Tully, J. G. 1989. Class Mollicutes: New perspectives from plant and arthropod studies. Pages 1-31 in: The Mycoplasmas. Vol. 5. R. F. Whitcomb and J. G. Tully, eds. Academic Press, New York.

21. Williamson, D. L., Tully, J. G., and Whitcomb, R. F. 1989. The genus Spiroplasma. Pages 71-111 in: The Mycoplasmas. Vol. 5. R. F. Whitcomb and J. G. Tully, eds. Academic Press, New York.

22. Yang, T., Davies, P. J., and Reid, J. B. 1996. Genetic dissection of the relative roles of auxins and gibberellin in the regulation of stem elongation in intact light-grown peas. Plant Physiol. 110:1029-1034.

23. Yu, F. 1997. Pigment content and in vitro culture of periwinkle infected with aster yellows phytoplasma or Spiroplasma citri. M.S. thesis. University of Georgia, Griffin.

24. Yu, F., and Chang, C. J. 1997. Effects of growth regulators on periwinkles associated with aster yellows phytoplasma or Spiroplasma citri. (Abstr.) Phytopathology 87(Suppl.):S107. 